\title{
PENENTUAN BILANGAN KROMATIK LOKASI GRAF THORN DARI GRAF RODA $W_{3}$
}

\author{
ELVA RAHIMAH, LYRA YULIANTI, DES WELYYANTI \\ Jurusan Matematika, \\ Fakultas Matematika dan Ilmu Pengetahuan Alam, Universitas Andalas, \\ Kampus UNAND Limau Manis Padang, Indonesia. \\ email : elva.rahimah@ymail.com
}

\begin{abstract}
Abstrak. Misalkan $G=(V, E)$ graf terhubung. Bilangan kromatik dari graf $G$ adalah bilangan asli terkecil $k$ sedemikian sehingga $G$ mempunyai suatu pewarnaan- $k$ titik sejati. Bilangan kromatik dari $G$ dinotasikan dengan $\chi(G)$. Misalkan $\chi(G)=k$, ini berarti titiktitik di $G$ paling kurang diwarnai dengan $k$ warna dan tidak dapat diwarnai dengan $k-1$ warna, sementara jika titik-titik di $G$ diwarnai dengan $k$ warna maka tidak ada titik yang bertetangga mempunyai warna yang sama.

Kelas warna pada $G$ dinotasikan dengan $S_{i}$, merupakan himpunan titik-titik yang berwarna $i$ dengan $1 \leq i \leq k$. Misalkan $\Pi=\left\{S_{1}, S_{2}, \cdots, S_{k}\right\}$ merupakan partisi terurut dari $V(G)$. Berdasarkan suatu pewarnaan titik, maka representasi v terhadap $\Pi$ disebut kode warna dari $v$, dinotasikan dengan $c_{\Pi}(v)$. Kode warna $c_{\Pi}(v)$ dari suatu titik $v \in$ $V(G)$ didefinisikan sebagai $k$-vektor

$$
c_{\Pi}(v)=\left(d\left(v, S_{1}\right), d\left(v, S_{2}\right), \cdots, d\left(v, S_{k}\right)\right),
$$

dimana $d\left(v, S_{i}\right)=\min \left\{d(v, x) \mid x \in S_{i}\right\}$ untuk $1 \leq i \leq k$. Jika setiap titik yang berbeda di $G$ memiliki kode warna yang berbeda untuk suatu $\Pi$, maka $c$ disebut pewarnaan lokasi dari $G$. Minimum dari banyaknya warna yang digunakan pada pewarnaan lokasi dari graf $G$ disebut bilangan kromatik lokasi. Pada tulisan ini akan dibahas bilangan kromatik lokasi graf thorn dari graf roda $W_{3}$.
\end{abstract}

Kata Kunci: Kelas warna, kode warna, bilangan kromatik lokasi, graf thorn, graf roda

\section{Pendahuluan}

Pewarnaan graf diyakini pertama kali muncul sebagai masalah pewarnaan peta, dimana warna setiap daerah pada peta yang berbatasan dibuat berlainan sehingga mudah untuk dibedakan. Masalah pewarnaan graf juga memiliki banyak aplikasi di dalam bidang lain. Salah satunya adalah pembuatan suatu jadwal, yang bertujuan agar waktu dan tempat yang sudah diatur sedemikian mungkin tidak saling tumpang tindih.

Konsep pewarnaan lokasi pertama kali dikaji oleh Chartrand dkk. [1] pada tahun 2002 dengan menentukan bilangan kromatik lokasi dari beberapa graf sebagai berikut, untuk graf lintasan $P_{n}$ dengan $n \geq 3$ diperoleh $\chi_{L}\left(P_{n}\right)=3$. Untuk graf siklus diperoleh $\chi_{L}\left(C_{n}\right)=3$ untuk n ganjil atau $\chi_{L}\left(C_{n}\right)=4$ untuk n genap. Selanjutnya, juga diperoleh bilangan kromatik lokasi untuk graf multipartit lengkap dan graf bintang ganda.

Pada tahun 2003, Chartrand dkk. [3] mengkarakterisasi graf orde $n$ dengan bilangan kromatik lokasi $n-1$. Karena masih sedikit bilangan kromatik lokasi yang 
diketahui, maka topik pewarnaan lokasi menarik untuk dikaji lebih lanjut. Untuk itu pada tulisan ini akan dibahas bilangan kromatik lokasi untuk graf thorn dari graf roda, dinotasikan graf $T h\left(W_{n}, \ell_{0}, \ell_{1}, \cdots, \ell_{n}\right)$, yaitu $\chi_{L}\left(T h\left(W_{n}, \ell_{0}, \ell_{1}, \cdots, \ell_{n}\right)\right)$.

\section{Definisi dan Terminologi dalam Teori Graf}

Graf Roda (Wheel) dilambangkan dengan $W_{n}$ dengan $n \geq 3$, adalah graf yang dikonstruksi dari suatu graf lingkaran $C_{n}$, dengan banyak titik $n \geq 3$, dengan cara menambahkan satu titik yang bertetangga dengan setiap titik pada graf lingkaran. Dinotasikan

$$
\begin{aligned}
& V\left(W_{n}\right)=\left\{v_{i} \mid 0 \leq i \leq n\right\} \\
& E\left(W_{n}\right)=\left\{v_{0} v_{j} \mid 1 \leq j \leq n\right\} \cup\left\{v_{k} v_{k+1} \mid 1 \leq k \leq n-1\right\} \cup\left\{v_{1} v_{n}\right\}
\end{aligned}
$$

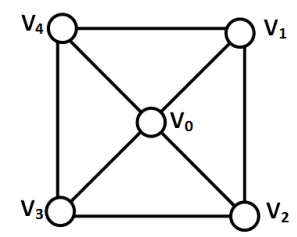

Gambar 1. Contoh Graf Roda $W_{4}$

Graf thorn dari graf roda, dinotasikan $T h\left(W_{n}, \ell_{0}, \ell_{1}, \cdots, \ell_{n}\right)$, adalah graf yang dikonstruksi dari graf roda $W_{n}$ dengan cara sebagai berikut. Pada setiap titik $v_{i}$ untuk $0 \leq i \leq n$ di $W_{n}$ ditambahkan daun sebanyak $\ell_{i}$ untuk $i \in\{0,1, \cdots, n\}$ dengan $\ell_{i} \geq 1$. Notasikan $m=\ell_{\max }=\max \left\{\ell_{0}, \ell_{1}, \cdots, \ell_{n}\right\}$ yang merupakan banyak daun maksimum. Selanjutnya, notasikan $v_{i j}$ sebagai titik ke-j yang bertetangga dengan $v_{i}$ pada graf $W_{n}$, untuk $0 \leq i \leq n$ dan $1 \leq j \leq \ell_{i}$.

Dapat dilihat bahwa himpunan titik dan himpunan sisi dari graf $T h\left(W_{n}, \ell_{0}, \ell_{1}, \cdots, \ell_{n}\right)$ adalah:

$$
\begin{aligned}
& V\left(T h\left(W_{n}, \ell_{0}, \ell_{1}, \cdots, \ell_{n}\right)\right)=\left\{v_{i} \mid 0 \leq i \leq n\right\} \cup\left\{v_{i j} \mid 0 \leq i \leq n, 1 \leq j \leq \ell_{i}\right\}, \\
& E\left(T h\left(W_{n}, \ell_{0}, \ell_{1}, \cdots, \ell_{n}\right)\right)=E\left(W_{n}\right) \cup\left\{v_{i} v_{i j} \mid 0 \leq i \leq n, 1 \leq j \leq \ell_{i}\right\}
\end{aligned}
$$

Graf thorn untuk graf roda diperlihatkan pada Gambar 2.

\section{Bilangan Kromatik Lokasi}

Bilangan kromatik (chromatic number) dari graf $G$ adalah bilangan asli terkecil $k$ sedemikian sehingga $G$ mempunyai suatu pewarnaan- $k$ titik sejati. Bilangan kromatik dari $G$ dinotasikan dengan $\chi(G)$. Misalkan $\chi(G)=k$, ini berarti titik-titik di $G$ paling kurang diwarnai dengan $k$ warna dan tidak dapat diwarnai dengan $k-1$ warna. Jika titik-titik di $G$ diwarnai dengan $k$ warna maka tidak ada titik yang bertetangga mempunyai warna yang sama. 


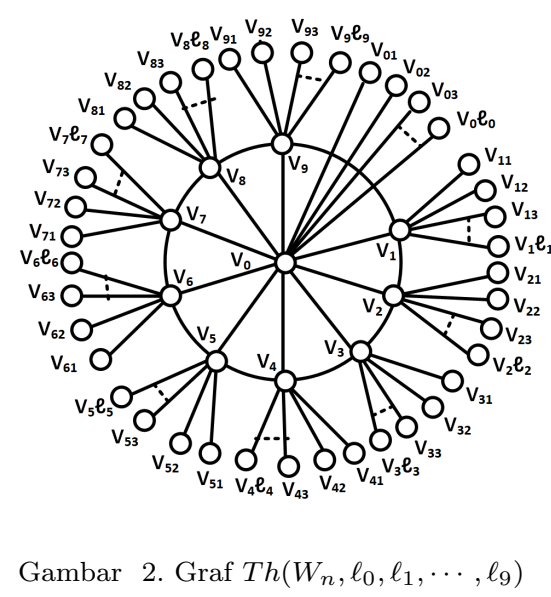

Kelas warna pada $G$ dinotasikan dengan $S_{i}$, merupakan himpunan titik-titik yang berwarna $i$ dengan $1 \leq i \leq k$. Misalkan $\Pi=\left\{S_{1}, S_{2}, \cdots, S_{k}\right\}$ merupakan partisi terurut dari $V(G)$. Berdasarkan suatu pewarnaan titik, maka representasi $\mathrm{v}$ terhadap $\Pi$ disebut kode warna dari $v$, dinotasikan dengan $c_{\Pi}(v)$. Kode warna $c_{\Pi}(v)$ dari suatu titik $v \in V(G)$ didefinisikan sebagai $k$-vektor,

$$
c_{\Pi}(v)=\left(d\left(v, S_{1}\right), d\left(v, S_{2}\right), \cdots, d\left(v, S_{k}\right)\right),
$$

dimana $d\left(v, S_{i}\right)=\min \left\{d(v, x) \mid x \in S_{i}\right\}$ untuk $1 \leq i \leq k$. Jika setiap titik yang berbeda di $G$ memiliki kode warna yang berbeda untuk suatu $\Pi$, maka $c$ disebut pewarnaan lokasi (locating-coloring) dari $G$. Minimum dari banyaknya warna yang digunakan pada pewarnaan lokasi dari graf $G$ disebut bilangan kromatik lokasi (locating-chromatic number).

Chartrand dkk. (2002) telah memberikan teorema dasar terkait bilangan kromatik lokasi suatu graf. Teorema tersebut dijelaskan pada teorema-teorema di bawah ini. Definisikan $N(v)$ sebagai himpunan yang berisi semua titik yang menjadi tetangga dari $v$.

Teorema 3.1. [2] Misalkan c adalah suatu pewarnaan lokasi pada graf terhubung $G$. Jika u dan $v$ adalah dua titik pada graf $G$ sedemikian sehingga $d(u, w)=d(v, w)$ untuk setiap $w \in V(G) \backslash\{u, v\}$, maka $c(u) \neq c(v)$. Dalam hal khusus, jika u dan $v$ adalah titik-titik yang tidak bertetangga di $G$ sedemikian sehingga $N(u)=N(v)$, maka $c(u) \neq c(v)$.

Bukti. Misalkan $c$ adalah suatu pewarnaan lokasi pada graf terhubung $G$. Misalkan $\Pi=\left(S_{1}, S_{2}, \cdots, S_{k}\right)$ adalah partisi dari himpunan titik-titik di $G$ dengan $S_{i}$ menyatakan kelas warna untuk $1 \leq i \leq k$. Untuk suatu titik $u, v \in V(G)$, andaikan $c(u)=c(v)$ sedemikian sehingga titik $u$ dan $v$ berada dalam kelas warna yang sama. Akibatnya, $d\left(u, S_{i}\right)=d\left(v, S_{i}\right)=0$. Karena $d(u, w)=d(v, w)$ untuk setiap $w \in V(G) \backslash\{u, v\}$ maka $d\left(u, S_{j}\right)=d\left(v, S_{j}\right)$ untuk setiap $j \neq i, 1 \leq j \leq k$. Akibatnya, $c_{\Pi}(u)=c_{\Pi}(v)$ sehingga $c$ bukan pewarnaan lokasi. Dengan demikian, haruslah 
$c(u) \neq c(v)$.

Akibat 3.2. [2] Jika $G$ adalah suatu graf terhubung yang memuat suatu titik yang bertetangga dengan $k$ daun di $G$, maka $\chi_{L}(G) \geq k+1$.

Bukti. Misalkan $v$ adalah suatu titik yang bertetangga dengan $k$ daun $x_{1}, x_{2} \cdots, x_{k}$ di $G$. Dari Teorema 3.1 setiap pewarnaan lokasi dari G mempunyai warna berbeda untuk setiap $x_{i}, i=1,2, \cdots, k$. Karena $v$ bertetangga dengan semua $x_{i}$, maka $v$ harus mempunyai warna yang berbeda dengan semua daun $x_{i}$. Akibatnya diperoleh bahwa, $X_{L}(G) \geq k+1$.

Pada Teorema 3.3 diberikan bilangan kromatik lokasi dari graf roda $W_{n}$ untuk $n \geq 3$.

Teorema 3.3. [4] Untuk $n \geq 3$, misalkan $W_{n}=K_{1}+C_{n}$ dan $r=\min \{k \in N \mid n \neq$ $\left.\frac{1}{2}\left(k^{3}-k^{2}\right)\right\} \cdot$ Maka,

$$
\chi_{L}\left(W_{n}\right)= \begin{cases}1+\chi_{L}\left(C_{n}\right), & 3 \leq n<9, \\ r+1, & n \neq \frac{1}{2}\left(r^{3}-r^{2}\right)-1 \text { dan } n \geq 9, \\ r+2, & n=\frac{1}{2}\left(r^{3}-r^{2}\right)-1 \text { dan } n \geq 9 .\end{cases}
$$

\section{Bilangan Kromatik Lokasi Graf Thorn untuk Graf Roda}

Misalkan terdapat graf $G \simeq T h\left(W_{3}, \ell_{0}, \ell_{1}, \cdots, \ell_{3}\right)$. Pada Teorema 4.1 diberikan bilangan kromatik lokasi dari $G$.

Teorema 4.1. $\diamond$ Misalkan terdapat graf $G \simeq T h\left(W_{3}, \ell_{0}, \ell_{1}, \cdots, \ell_{3}\right)$. Maka

$$
\chi_{L}(G)= \begin{cases}4, & m \leq 3, \\ m+1, & m>3 .\end{cases}
$$

Bukti. Algoritma penentuan bilangan kromatik lokasi dari graf $G$ adalah sebagai berikut:

(1) Berikan $c\left(v_{0}\right)=1$,

(2) Berikan warna pada titik $v_{i}$, sebagai berikut:

$$
c\left(v_{i}\right)=i+1 \text { untuk } 1 \leq i \leq 3,
$$

(3) Berikan warna pada titik daun $v_{i j}$ dengan $i \in[1,3], j \in[1, m]$ yang terkait pada setiap titik di $W_{3}$. Jika terdapat titik $v_{i}$ di $W_{3}$ dengan warna setiap titik di $W_{3}$ berbeda maka berikan warna $v_{i j}$ yang sesuai. Karena $v_{i}$ bertetangga dengan $v_{i j}$ maka $c\left(v_{i}\right) \neq c\left(v_{i j}\right)$. Tuliskan $m=\ell_{\max }=\max \left\{\ell_{0}, \ell_{1}, \ell_{2}, \ell_{3}\right\}$

(4) Karena $d\left(u, S_{i}\right) \neq d\left(v, S_{i}\right)$ untuk suatu $1 \leq i \leq k$ maka $c_{\Pi}(u) \neq c_{\Pi}(v)$ untuk setiap $u, v \in V(G)$.

Berdasarkan algoritma di atas akan ditentukan:

(1) Akan ditunjukkan $\chi_{L}(G)=4$ untuk $m \leq 3$. 


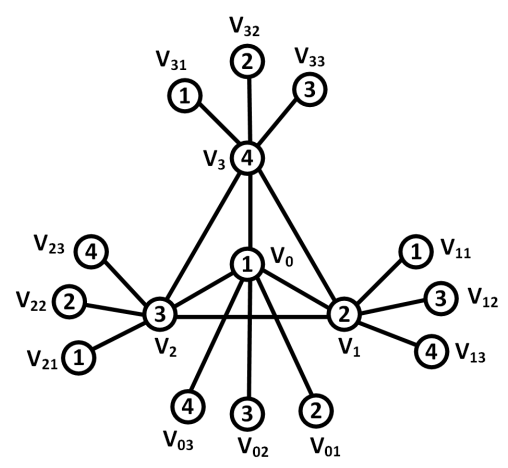

Gambar 3. Pewarnaan Lokasi dari Graf $T h\left(W_{3}, \ell_{0}, \ell_{1}, \ell_{2}, \ell_{3}\right)$ untuk $m \leq 3$

(a) Akan ditunjukkan bahwa $\chi_{L}(G) \leq 4$ untuk $m \leq 3$.

Definisikan pewarnaan titik di $G$ sebagai berikut $c: V(G) \rightarrow\{1,2,3,4\}$ sedemikian sehingga,

$$
\begin{aligned}
c\left(v_{0}\right) & =1, \\
c\left(v_{s}\right) & =a+1 \text { untuk } 1 \leq a \leq 3, \\
c\left(v_{i j}\right) & =[1,4] \backslash\left\{c\left(v_{i}\right)\right\} \text { untuk } 0 \leq i \leq 3, \text { dan } 1 \leq j \leq 3 .
\end{aligned}
$$

Akan ditunjukkan bahwa kode warna setiap titik di $G$ berbeda terhadap $\Pi$. Berdasarkan pewarnaan $c$ di atas, diperoleh bahwa $\Pi=\left\{S_{1}, S_{2}, \cdots, S_{4}\right\}$ dengan

$S_{1}=\left\{v_{0}, v_{11}, v_{21}, v_{31}\right\}, S_{2}=\left\{v_{1}, v_{01}, v_{22}, v_{32}\right\}, S_{3}=\left\{v_{2}, v_{02}, v_{12}, v_{33}\right\}, S_{4}=\left\{v_{3}, v_{03}, v_{13}, v_{23}\right\}$

Kode warna setiap titik di $G$ terhadap $\Pi$ sebagai berikut,

$$
\begin{aligned}
c_{\Pi}\left(v_{0}\right) & =\left(d\left(v_{0}, S_{1}\right), d\left(v_{0}, S_{2}\right), d\left(v_{0}, S_{3}\right), d\left(v_{0}, S_{4}\right)\right), \\
& =\left(d\left(v_{0}, v_{0}\right), d\left(v_{0}, v_{1}\right), d\left(v_{0}, v_{2}\right), d\left(v_{0}, v_{3}\right)\right), \\
& =(0,1,1,1), \\
c_{\Pi}\left(v_{1}\right) & =\left(d\left(v_{1}, S_{1}\right), d\left(v_{1}, S_{2}\right), d\left(v_{1}, S_{3}\right), d\left(v_{1}, S_{4}\right)\right), \\
& =\left(d\left(v_{1}, v_{0}\right), d\left(v_{1}, v_{1}\right), d\left(v_{1}, v_{2}\right), d\left(v_{1}, v_{3}\right)\right), \\
& =(1,0,1,1), \\
c_{\Pi}\left(v_{2}\right) & =\left(d\left(v_{2}, S_{1}\right), d\left(v_{2}, S_{2}\right), d\left(v_{2}, S_{3}\right), d\left(v_{2}, S_{4}\right)\right), \\
& =\left(d\left(v_{2}, v_{0}\right), d\left(v_{2}, v_{1}\right), d\left(v_{2}, v_{2}\right), d\left(v_{2}, v_{3}\right)\right), \\
& =(1,1,0,1), \\
c_{\Pi}\left(v_{3}\right) & =\left(d\left(v_{3}, S_{1}\right), d\left(v_{3}, S_{2}\right), d\left(v_{3}, S_{3}\right), d\left(v_{3}, S_{4}\right)\right), \\
& =\left(d\left(v_{3}, v_{0}\right), d\left(v_{3}, v_{1}\right), d\left(v_{3}, v_{2}\right), d\left(v_{3}, v_{3}\right)\right), \\
& =(1,1,1,0),
\end{aligned}
$$


Selanjutnya, diperoleh juga

$$
\begin{aligned}
& c_{\Pi}\left(v_{01}\right)=(1,0,2,2), c_{\Pi}\left(v_{12}\right)=(2,1,0,2), c_{\Pi}\left(v_{23}\right)=(2,2,1,0), \\
& c_{\Pi}\left(v_{02}\right)=(1,2,0,2), c_{\Pi}\left(v_{13}\right)=(2,1,2,0), c_{\Pi}\left(v_{31}\right)=(0,2,2,1), \\
& c_{\Pi}\left(v_{03}\right)=(1,2,2,0), c_{\Pi}\left(v_{21}\right)=(0,2,1,2), c_{\Pi}\left(v_{32}\right)=(2,0,2,1), \\
& c_{\Pi}\left(v_{11}\right)=(0,1,2,2), c_{\Pi}\left(v_{22}\right)=(2,0,1,2), c_{\Pi}\left(v_{33}\right)=(2,2,0,1) .
\end{aligned}
$$

Dari kode warna di atas dapat dilihat bahwa, setiap titik di $G$ memiliki kode warna yang berbeda. Jadi, haruslah $\chi_{L}(G) \leq 4$ untuk $m \leq 3$.

(b) Akan ditunjukkan bahwa $\chi_{L}(G) \geq 4$ untuk $m \leq 3$.

Dari Teorema 3.3 diperoleh bahwa $\chi_{L}\left(W_{3}\right)=4$. Karena $1 \leq m \leq 3$ maka bilangan kromatik lokasi graf thorn dari $W_{3}$ mengikuti bilangan kromatik lokasi graf $W_{3}$. Jadi, haruslah $\chi_{L}(G) \geq 4$ untuk $m \leq 3$. Maka dapat disimpulkan bahwa $\chi_{L}(G)=4$ untuk $m \leq 3$.

(2) Akan ditunjukkan bahwa $\chi_{L}(G)=m+1$ untuk $m>3$.

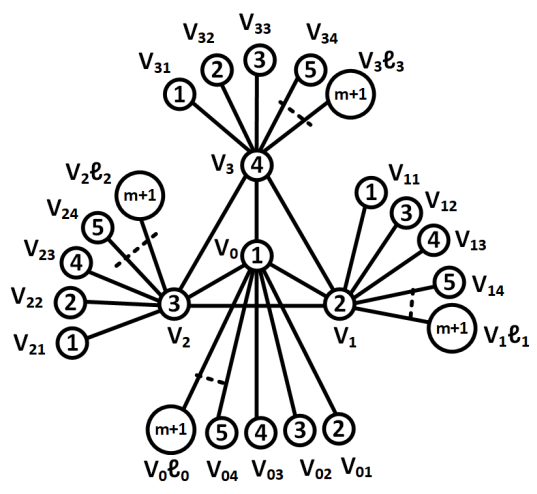

Gambar 4. Pewarnaan Lokasi dari Graf $T h\left(W_{3}, \ell_{0}, \ell_{1}, \ell_{2}, \ell_{3}\right)$ untuk $m>3$.

(a) Akan ditunjukkan bahwa $\chi_{L}(G) \leq m+1$ untuk $m>3$.

Definisikan pewarnaan titik di $G$ sebagai berikut $c: V(G) \rightarrow$ $\{1,2,3, \cdots, m+1\}$ sedemikian hingga,

$$
\begin{aligned}
c\left(v_{0}\right) & =1, \\
c\left(v_{a}\right) & =a+1 \text { untuk } 1 \leq a \leq 3, \\
c\left(v_{i j}\right) & =[1, m+1] \backslash\left\{c\left(v_{i}\right)\right\} \text { untuk } 0 \leq i \leq 3 \text { dan } 1 \leq j \leq \ell_{i} .
\end{aligned}
$$

Maka diperoleh kelas warna sebagai berikut $\Pi=\left\{S_{1}, S_{2}, \cdots, S_{m+1}\right\}$ dengan,

$S_{1}=\left\{v_{0}, v_{11}, v_{21}, v_{31}\right\}, S_{2}=\left\{v_{1}, v_{01}, v_{22}, v_{32}\right\}, S_{3}=\left\{v_{2}, v_{02}, v_{12}, v_{33}\right\}$

$S_{4}=\left\{v_{3}, v_{03}, v_{13}, v_{23}\right\}, S_{5}=\left\{v_{04}, v_{14}, v_{24}, v_{34}\right\}, \cdots, S_{m+1}=\left\{v_{0 m}, v_{1 m}, v_{2 m}, v_{3 m}\right\}$ 
Akibatnya diperoleh kode warna setiap titik di $G$ terhadap $\Pi$ sebagai berikut,

$$
\begin{aligned}
c_{\Pi}\left(v_{0}\right) & =\left(d\left(v_{0}, S_{1}\right), d\left(v_{0}, S_{2}\right), d\left(v_{0}, S_{3}\right), d\left(v_{0}, S_{4}\right), d\left(v_{0}, S_{5}\right), \cdots, d\left(v_{0}, S_{m+1}\right)\right), \\
& =\left(d\left(v_{0}, v_{0}\right), d\left(v_{0}, v_{1}\right), d\left(v_{0}, v_{2}\right), d\left(v_{0}, v_{3}\right), d\left(v_{0}, S_{5}\right), \cdots, d\left(v_{0}, S_{m+1}\right)\right), \\
& =\left(0,1,1,1, d\left(v_{0}, S_{5}\right), \cdots, d\left(v_{0}, S_{m+1}\right)\right), \\
c_{\Pi}\left(v_{1}\right) & =\left(d\left(v_{1}, S_{1}\right), d\left(v_{1}, S_{2}\right), d\left(v_{1}, S_{3}\right), d\left(v_{1}, S_{4}\right), d\left(v_{1}, S_{5}\right), \cdots, d\left(v_{1}, S_{m+1}\right)\right), \\
& =\left(d\left(v_{1}, v_{0}\right), d\left(v_{1}, v_{1}\right), d\left(v_{1}, v_{2}\right), d\left(v_{1}, v_{3}\right), d\left(v_{1}, S_{5}\right), \cdots, d\left(v_{1}, S_{m+1}\right)\right), \\
& =\left(1,0,1,1, d\left(v_{1}, S_{5}\right), \cdots, d\left(v_{1}, S_{m+1}\right)\right), \\
c_{\Pi}\left(v_{2}\right) & =\left(d\left(v_{2}, S_{1}\right), d\left(v_{2}, S_{2}\right), d\left(v_{2}, S_{3}\right), d\left(v_{2}, S_{4}\right), d\left(v_{2}, S_{5}\right), \cdots, d\left(v_{2}, S_{m+1}\right)\right), \\
& =\left(d\left(v_{2}, v_{0}\right), d\left(v_{2}, v_{1}\right), d\left(v_{2}, v_{2}\right), d\left(v_{2}, v_{3}\right), d\left(v_{2}, S_{5}\right), \cdots, d\left(v_{2}, S_{m+1}\right)\right), \\
& =\left(1,1,0,1, d\left(v_{2}, S_{5}\right), \cdots, d\left(v_{2}, S_{m+1}\right)\right), \\
c_{\Pi}\left(v_{3}\right) & =\left(d\left(v_{3}, S_{1}\right), d\left(v_{3}, S_{2}\right), d\left(v_{3}, S_{3}\right), d\left(v_{3}, S_{4}\right), d\left(v_{3}, S_{5}\right), \cdots, d\left(v_{3}, S_{m+1}\right)\right), \\
& =\left(d\left(v_{3}, v_{0}\right), d\left(v_{3}, v_{1}\right), d\left(v_{3}, v_{2}\right), d\left(v_{3}, v_{3}\right), d\left(v_{3}, S_{5}\right), \cdots, d\left(v_{3}, S_{m+1}\right)\right), \\
& =\left(1,1,1,0, d\left(v_{3}, S_{5}\right), \cdots, d\left(v_{3}, S_{m+1}\right)\right),
\end{aligned}
$$

Selanjutnya, diperoleh juga

$$
\begin{aligned}
c_{\Pi}\left(v_{01}\right) & =\left(1,0,2,2, d\left(v_{01}, S_{5}\right), \cdots, d\left(v_{01}, S_{m+1}\right)\right), \\
c_{\Pi}\left(v_{02}\right) & =\left(1,2,0,2, d\left(v_{02}, S_{5}\right), \cdots, d\left(v_{02}, S_{m+1}\right)\right), \\
c_{\Pi}\left(v_{03}\right) & =\left(1,2,2,0, d\left(v_{03}, S_{5}\right), \cdots, d\left(v_{03}, S_{m+1}\right)\right), \\
c_{\Pi}\left(v_{04}\right) & =\left(1,2,2,2,0, \cdots, d\left(v_{04}, S_{m+1}\right)\right), \\
\vdots & \\
c_{\Pi}\left(v_{0 m}\right) & =(1,2,2,2,2, \cdots, 0), \\
c_{\Pi}\left(v_{11}\right) & =\left(0,1,2,2, d\left(v_{11}, S_{5}\right), \cdots, d\left(v_{11}, S_{m+1}\right)\right), \\
c_{\Pi}\left(v_{12}\right) & =\left(2,1,0,2, d\left(v_{12}, S_{5}\right), \cdots, d\left(v_{12}, S_{m+1}\right)\right), \\
c_{\Pi}\left(v_{13}\right) & =\left(2,1,2,0, d\left(v_{13}, S_{5}\right), \cdots, d\left(v_{13}, S_{m+1}\right)\right), \\
c_{\Pi}\left(v_{14}\right) & =\left(2,1,2,2,0, \cdots, d\left(v_{14}, S_{m+1}\right)\right), \\
\vdots & \\
c_{\Pi}\left(v_{1 m}\right) & =(2,1,2,2,2, \cdots, 0), \\
c_{\Pi}\left(v_{21}\right) & =\left(0,2,1,2, d\left(v_{21}, S_{5}\right), \cdots, d\left(v_{21}, S_{m+1}\right)\right), \\
c_{\Pi}\left(v_{22}\right) & =\left(2,0,1,2, d\left(v_{22}, S_{5}\right), \cdots, d\left(v_{22}, S_{m+1}\right)\right), \\
c_{\Pi}\left(v_{23}\right) & =\left(2,2,1,0, d\left(v_{23}, S_{5}\right), \cdots, d\left(v_{23}, S_{m+1}\right)\right), \\
c_{\Pi}\left(v_{24}\right) & =\left(2,2,1,2,0, \cdots, d\left(v_{24}, S_{m+1}\right)\right), \\
\vdots & \\
c_{\Pi}\left(v_{2 m}\right) & =(2,2,1,2,2, \cdots, 0),
\end{aligned}
$$




$$
\begin{aligned}
c_{\Pi}\left(v_{31}\right) & =\left(0,2,2,1, d\left(v_{31}, S_{5}\right), \cdots, d\left(v_{31}, S_{m+1}\right)\right), \\
c_{\Pi}\left(v_{32}\right) & =\left(2,0,2,1, d\left(v_{32}, S_{5}\right), \cdots, d\left(v_{32}, S_{m+1}\right)\right), \\
c_{\Pi}\left(v_{33}\right) & =\left(2,2,0,1, d\left(v_{33}, S_{5}\right), \cdots, d\left(v_{33}, S_{m+1}\right)\right), \\
c_{\Pi}\left(v_{34}\right) & =\left(2,2,2,1,0, \cdots, d\left(v_{34}, S_{m+1}\right)\right), \\
\vdots & \\
c_{\Pi}\left(v_{3 m}\right) & =(2,2,2,1,2, \cdots, 0) .
\end{aligned}
$$

Dari kode warna di atas dapat dilihat bahwa, setiap titik di $G$ mempunyai kode warna berbeda terhadap $\Pi$. Jadi, haruslah $\chi_{L}(G) \leq m+1$ untuk $m>3$.

(b) Akan ditunjukkan bahwa $\chi_{L}(G) \geq m+1$ untuk $m>3$.

Misalkan $\Pi=\left\{S_{1}, S_{2}, \cdots, S_{m+1}\right\}$. Tanpa mengurangi perumuman, misalkan terdapat sebanyak $m=\ell_{\max }$ daun dititik $v_{i}$ untuk suatu $i$. Dengan menggunakan Akibat 3.2 diperoleh $\chi_{L}(G) \geq m+1$ untuk $m>3$. Maka dapat disimpulkan bahwa $\chi_{L}(G)=m+1$ untuk $m>3$.

\section{Kesimpulan}

Berdasarkan pembahasan di bagian sebelumnya, dapat disimpulkan bahwa,

$$
\chi_{L}\left(T h\left(W_{3}, \ell_{0}, \ell_{1}, \ell_{2}, \ell_{3}\right)\right)= \begin{cases}4, & m \leq 3, \\ m+1, & m>3 .\end{cases}
$$

\section{Ucapan Terima kasih}

Terima kasih kepada bapak Narwen M.Si, bapak Dr. Effendi, dan ibu Radhiatul Husna M.Si selaku dosen penguji, yang telah memberikan kritik dan saran dalam penulisan makalah ini.

\section{Daftar Pustaka}

[1] Bondy, J.A dan Murty, U.S.R. 1976, Graph Theory with Application, The Macmillan Press LTD, London

[2] Chartrand, G., dkk., 2002, The Locating-Chromatic Number of a Graph, Bull. Inst. Combin. Appl, 36: $89-101$

[3] Chartrand, G., dkk., 2003, Graph of Order n with Locating-Chromatic Number n-1, Discrete Math, 269: 65 - 79

[4] Purwasih, I. A., dkk., 2013, The Locating Chromatic Number for a Subdivision of a Wheel on One Cycle Edge, Int. J. Graphs Comb., pp: $372-376$ 